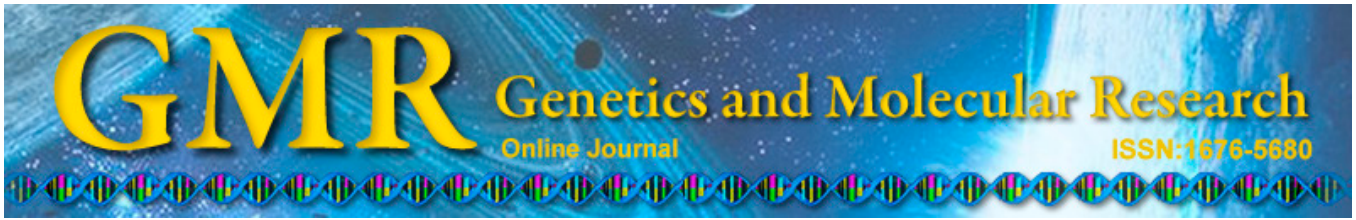

\title{
rbcS SRS4 promoter from Glycine max and its expression activity in transgenic tobacco
}

\author{
X.Y. Cui ${ }^{1}$, Z.Y. Chen ${ }^{2}$, L. Wu' ${ }^{1}$, X.Q. Liu' ${ }^{1}$, Y.Y. Dong', F.W. Wang ${ }^{3}$ and H.Y. Li ${ }^{1,3}$ \\ ${ }^{1}$ College of Life Sciences, Jilin Agricultural University, Changchun, China \\ ${ }^{2}$ College of Agronomy, Jilin Agricultural University, Changchun, China \\ ${ }^{3}$ Ministry of Education Engineering Research Center of Bioreactor and \\ Pharmaceutical Development, Jilin Agricultural University, Changchun, China \\ Corresponding author: H.Y. Li \\ E-mail: hyli99@163.com
}

Genet. Mol. Res. 14 (3): 7395-7405 (2015)

Received August 20, 2014

Accepted February 6, 2015

Published July 3, 2015

DOI http://dx.doi.org/10.4238/2015.July.3.15

\begin{abstract}
The regulatory region of the ribulose-1,5-bisphosphate carboxylase small subunit gene SRS4 from soybean (Glycine max) was cloned using TAIL-PCR and general PCR, and named the $r b c \mathrm{~S}$ promoter. The promoter was fused with the GUS gene and introduced into Nicotiana tabacum via Agrobacterium-mediated leaf disk transformation. In 4-week-old transgenic tobacco plants, the highest GUS expression levels were observed in the leaves, GUS activity was 7.13- and 7.40-fold higher in leaves than in stems and roots, respectively. Moreover, GUS activity was stimulated by light. In conclusion, spatial and light regulation of the soybean $r b c \mathrm{~S}$ promoter was observed in N. tabacum, thus illustrating a leaf-specific and light-induced promoter.
\end{abstract}

Key words: Soybean; $r b c$ S promoter; Transgenic tobacco; GUS activity 


\section{INTRODUCTION}

Soybean (Glycine max) is an important worldwide crop, and an important source of vegetable oil and protein (Cho et al., 1995). There is a large interest in improving soybean quality and production through genetic engineering (Wang and $\mathrm{Xu}, 2008$ ). One strategy for regulating and improving the expression of foreign beneficial genes in transgenic plants is through the manipulation of gene promoters. This enables high expression of a gene of interest, allowing precise temporal and spatial regulation in specific plant parts (Khoudi et al., 1997). The promoter of the Rubisco small subunit is a useful tool to target expression of foreign genes specifically to plant leaves, and is regulated by light (Bakhsh et al., 2011).

Ribulose-1,5-bisphosphate carboxylase/oxygenase $(r b c \mathrm{~S}$; EC.4.1.1.39) is the most prevalent enzyme in higher plants, accounting for $30-50 \%$ of total soluble protein in the chloroplast. It catalyzes the primary step in photosynthetic carbon dioxide fixation, and is severely limited by oxygenase activity. The ratio of carboxylation and oxygenation reactions governs plant productivity (Dhingra et al., 2004). The structural composition of Rubisco consists of eight large and eight small subunits, encoded by nuclear gene families and chloroplast genomes, respectively (Dean et al., 1989). Members of the $r b c$ S gene family encode the small subunits of Rubisco, their expression is regulated by light, and regulation occurs primarily at the transcriptional level (Kyozuka et al., 1993). $r b c \mathrm{~S}$ transcripts are distributed in a tissuespecific manner, especially to photosynthetic organs; this is because transit peptides target proteins to chloroplasts and mitochondria (Spreitzer, 2003; Zhong et al., 2003).

The $r b c \mathrm{~S}$ promoter has been cloned, sequenced, and studied in various plants, including pea (Pisum sativum; Nagy et al., 1985), cotton (Gossypium spp; Song et al., 2000), Chrysanthemum (Outchkourov et al., 2003), coffee (Coffea arabica; Marraccini et al., 2003), and potato (Solanum tuberosum L.; Qu et al., 2011). In soybean, the $r b c \mathrm{~S}$ gene family comprises 6-10 members (Dean et al., 1989). To date, only two genes, SRS1 and SRS4, have been investigated (Berry-Lowe et al., 1982; Berry-Lowe and Meagher, 1985; Grandbastien et al., 1986). Reporter genes are reported to be regulated by the soybean $r b c$ S SRS1 promoter in a tissue-specific and light-induced manner in heterologous plants (Quandt et al., 1992; Gittins et al., 2000; Marraccini et al., 2003).

In this study, the 5 '-flanking sequence of the soybean $r b c \mathrm{~S}$ promoter was initially cloned using Thermal Asymmetric Interlaced PCR (TAIL-PCR), and the full-length sequence obtained using general PCR; the sequence, structure, and functions were then analyzed.

\section{MATERIAL AND METHODS}

\section{Isolation of genomic DNA and cloning of the $r b c S$ promoter}

Glycine max cv. Jinong 13 plants were grown in an incubator stimulating normal growth conditions, as described by Bustamante et al. (2009). Genomic DNA was extracted from leaf tissue collected from 4-week-old plants. DNA concentration and purity was analyzed using gel electrophoresis and UV-spectrophotometry.

The 5'-flanking sequence of the soybean $r b c$ S promoter was amplified by TAIL-PCR, as described by Liu and Whittier (1995), with slight modifications. Three nested gene-specific primers (SP1, SP2, and SP3) were designed according to the published RuBPcase (ribulose-1,5-bisphosphate carboxylase) small subunit gene sequence (GenBank accession No. 
M16889), a further three arbitrary degenerate primers (AD1, AD2, and AD3) were provided by the Academy of Agricultural Sciences in Jilin Province, China. Resultant PCR products were analyzed using agarose gel electrophoresis. A target fragment (TAIL1) of approximately $900 \mathrm{bp}$ was obtained and sequenced. The specific primer SS was synthesized according to the TAIL-PCR product sequence, while the SA primer was obtained from the sequence of the $r b c \mathrm{~S}$ gene. PCR products, now named $r b c \mathrm{SP}$, were cloned using primers SS and SA, with genomic Soybean Jinong 13 DNA as template. Following electrophoreses, the $r b c$ SP product was extracted from gels and cleaned using an AxyPrep PCR Clean-up kit (Corning, China). Next, the $r b c \mathrm{SP}$ fragment was ligated into a pMD18-T vector (Takara, China) to generate the recombinant plasmid pT-rbcSP, and sequenced. All primers used and the TAIL-PCR procedure are shown in Tables 1 and 2, respectively.

Table 1. Primers used in TAIL-PCR and general PCR of the soybean $r b c \mathrm{~S}$ SRS4 promoter.

\begin{tabular}{ll}
\hline Name & Sequences \\
\hline $\mathrm{AD}^{\mathrm{a}}$ & 5'-NGTCGASWGANAWGAA-3' \\
$\mathrm{AD}^{\mathrm{a}}$ & 5'-WGTGNAGWANCANAGA-3' \\
$\mathrm{AD}^{\mathrm{a}}$ & 5'-AGWGNAGWANCAWAGG-3' \\
$\mathrm{SP}^{\mathrm{a}}$ & 5'-AATGTGTGATGGTGGTGGAGTTT-3' \\
$\mathrm{SP}^{\mathrm{a}}$ & 5'-CACTCTTATCCATTTTGTTGGGTAG-3' \\
$\mathrm{SP}^{\mathrm{a}}$ & 5'-ATAGAAGGGGATGGTAGGTGATGGG-3' \\
$\mathrm{SS}^{\mathrm{b}}$ & 5'-GTGGATGACTCAAGTGCTGG-3' \\
$\mathrm{SA}^{\mathrm{b}}$ & 5'-TGCATTGCACTCTTCCACCG-3' \\
\hline
\end{tabular}

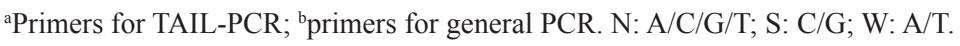

Table 2. TAIL-PCR procedure used to analyze the soybean $r b c$ S SRS4 promoter.

\begin{tabular}{|c|c|c|c|}
\hline Reaction & Regent $(\mu \mathrm{L})$ & Thermal cycling conditions & Cycle No. \\
\hline \multirow[t]{7}{*}{ Primary } & 10X LA PCR Buffer: 2.5 & $94^{\circ} \mathrm{C} 1 \mathrm{~min}, 98^{\circ} \mathrm{C} 1 \mathrm{~min}$ & 1 \\
\hline & dNTP mixture $(2.5 \mathrm{mM}): 4$ & $94^{\circ} \mathrm{C} 30 \mathrm{~s}, 55^{\circ} \mathrm{C} 1 \mathrm{~min}, 72^{\circ} \mathrm{C} 2 \mathrm{~min}$ & 5 \\
\hline & $\mathrm{AD}(1-3)(100 \mu \mathrm{M}): 0.5$ & $94^{\circ} \mathrm{C} 30 \mathrm{~s}, 25^{\circ} \mathrm{C} 3 \mathrm{~min}, 72^{\circ} \mathrm{C} 2 \mathrm{~min}$ & 1 \\
\hline & SP1 $(10 \mu \mathrm{M}): 0.5$ & $94^{\circ} \mathrm{C} 30 \mathrm{~s}, 55^{\circ} \mathrm{C} 1 \mathrm{~min}, 72^{\circ} \mathrm{C} 2 \mathrm{~min}$ & 15 \\
\hline & Genomic DNA: 0.5 & $94^{\circ} \mathrm{C} 30 \mathrm{~s}, 55^{\circ} \mathrm{C} 1 \mathrm{~min}, 72^{\circ} \mathrm{C} 2 \mathrm{~min}$ & \\
\hline & TaKaRa LA Taq $(5 \mathrm{U} / \mu \mathrm{L}): 0.5$ & $94^{\circ} \mathrm{C} 30 \mathrm{~s}, 43^{\circ} \mathrm{C} 1 \mathrm{~min}, 72^{\circ} \mathrm{C} 2 \mathrm{~min}$ & \\
\hline & $\mathrm{ddH}_{2} \mathrm{O}: 16.5$ & $72^{\circ} \mathrm{C} 10 \mathrm{~min}$ & 1 \\
\hline \multirow[t]{6}{*}{ Secondary } & 10X LA PCR Buffer: 2.5 & $94^{\circ} \mathrm{C} 30 \mathrm{~s}, 55^{\circ} \mathrm{C} 1 \mathrm{~min}, 72^{\circ} \mathrm{C} 2 \mathrm{~min}$ & 15 \\
\hline & dNTP mixture $(2.5 \mathrm{mM}): 4$ & $94^{\circ} \mathrm{C} 30 \mathrm{~s}, 55^{\circ} \mathrm{C} 1 \mathrm{~min}, 72^{\circ} \mathrm{C} 2 \mathrm{~min}$ & \\
\hline & $\mathrm{AD}(1-3)(100 \mu \mathrm{M}): 0.5$ & $94^{\circ} \mathrm{C} 30 \mathrm{~s}, 43^{\circ} \mathrm{C} 1 \mathrm{~min}, 72^{\circ} \mathrm{C} 2 \mathrm{~min}$ & \\
\hline & SP2 $(10 \mu \mathrm{M}): 0.5$ & $72^{\circ} \mathrm{C} 10 \mathrm{~min}$ & 1 \\
\hline & 1/50 primary PCR product: 1 & & \\
\hline & $\begin{array}{l}\text { TaKaRa LA Taq }(5 \mathrm{U} / \mu \mathrm{L}): 0.5 \\
\mathrm{ddH} \text { O: } 16\end{array}$ & & \\
\hline \multirow[t]{7}{*}{ Tertiary } & 10X LA PCR Buffer: 2.5 & $94^{\circ} \mathrm{C} 30 \mathrm{~s}, 55^{\circ} \mathrm{C} 1 \mathrm{~min}, 72^{\circ} \mathrm{C} 2 \mathrm{~min}$ & 15 \\
\hline & dNTP mixture $(2.5 \mathrm{mM}): 4$ & $94^{\circ} \mathrm{C} 30 \mathrm{~s}, 55^{\circ} \mathrm{C} 1 \mathrm{~min}, 72^{\circ} \mathrm{C} 2 \mathrm{~min}$ & \\
\hline & $\mathrm{AD}(1-3)(100 \mu \mathrm{M}): 0.5$ & $94^{\circ} \mathrm{C} 30 \mathrm{~s}, 43^{\circ} \mathrm{C} 1 \mathrm{~min}, 72^{\circ} \mathrm{C} 2 \mathrm{~min}$ & \\
\hline & $\mathrm{SP} 3(10 \mu \mathrm{M}): 0.5$ & $72^{\circ} \mathrm{C} 10 \mathrm{~min}$ & 1 \\
\hline & 1/100 primary PCR product: 1 & & \\
\hline & TaKaRa LA Taq $(5 \mathrm{U} / \mu \mathrm{L}): 0.5$ & & \\
\hline & $\mathrm{ddH}_{2} \mathrm{O}: 16$ & & \\
\hline
\end{tabular}

\section{DNA sequencing and bioinformatic analysis of the $r b c S$ promoter}

The pT-rbcSP plasmid was sequenced by Takara Bio (China) using M13 primers. Sequences were retrieved from the GenBank database using the BLASTn program. Sequence analysis was performed using the DNAman 5.2.2 software. Putative cis-acting elements in 
the promoter were identified using PlantCARE (http://bioinformatics.psb.ugent.be/webtools/ plantcare/html/) and PLACE (http://www.dna.affrc.go.jp/PLACE/) softwares.

\section{Expression vector construction and tobacco transformation}

The GrbcSP DNA fragment containing the soybean $r b c \mathrm{~S}$ promoter was amplified from the recombination plasmid pT-rbcSP using a 5'-oligonucleotide (5'-AACTGCAGGTGGATG ACTCAAGTGCTGG-3') with a PstI site and a 3'-oligonucleotide (5'-CATGCCATGGTGCAT TGCACTCTTCCACCG-3') with an $\mathrm{NcoI}$ site as primers. The PCR product and the plant expression vector pCAMBIA-1301 were double-digested with PstI and NcoI, respectively, and then ligated to construct the pCAMBIA-GrbcSP vector (Figure 1); this was sequenced to confirm presence of the $r b c \mathrm{~S}$ promoter.

Vectors pCAMBIA-GrbcSP and pCAMBIA-1301 were introduced into Agrobacterium tumefaciens strain LBA4404 using the tri-parental hybrid method. Positive recombined Agrobacterium LBA4404 colonies were selected and transformed into tobacco (Nicotiana tabacum cv. NC89) using the Agrobacterium-mediated leaf-disc method (Horsch et al., 1985). Transformed plants (named as prbcSP and p35SP plants, for pCAMBIA-GrbcSP and pCAMBIA-1301 vectors, respectively) were screened on MS medium supplemented with $50 \mathrm{mg} / \mathrm{L}$ kanamycin and $500 \mathrm{mg} / \mathrm{L}$ cephaloglycin. Plantlets were verified by PCR, using the primers 5'-TTCCTGATTAACCACAAACC-3' and 5'-CGGTTCGTTGGCAATACTCC-3'. All positive plants were transferred to soil and grown in a greenhouse at $25^{\circ} \mathrm{C}$ under a $16 / 8-\mathrm{h}$ light/dark regime. Tissues were collected, immediately frozen in liquid nitrogen, and stored at $-80^{\circ} \mathrm{C}$ until required.

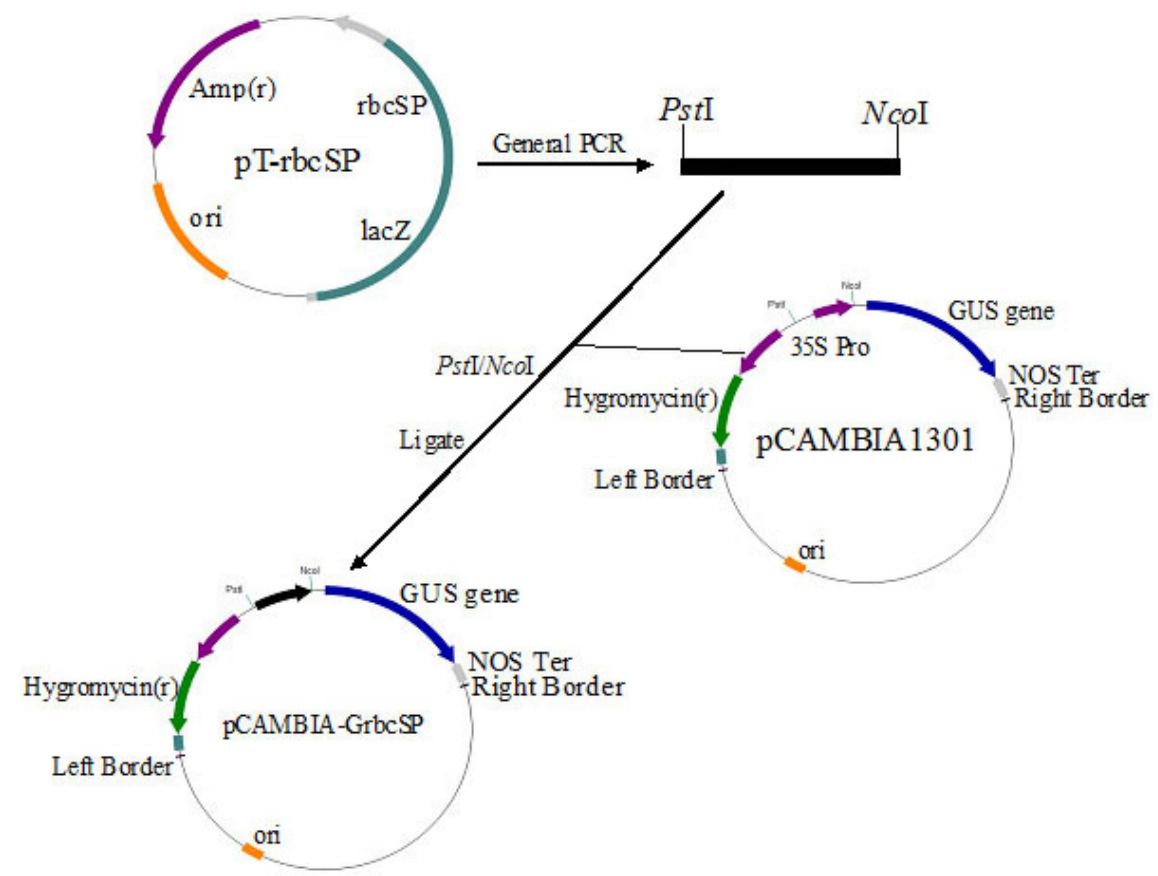

Figure 1. Construction of the expression vector pCAMBIA-GrbcSP. 


\section{Histochemical staining and fluorometric quantification of GUS activity}

To characterize the function of the $r b c \mathrm{~S}$ promoter, histochemical staining and fluorometric quantification were performed as described previously (Jefferson, 1987). Small sections of fresh tissues (leaves and roots) were immersed in GUS-staining solution $[50 \mathrm{mM}$ phosphate buffer, $\mathrm{pH} 7.0$, containing $1 \mathrm{mM} \mathrm{X-Gluc,} 0.01 \mathrm{M}$ disodium ethylenediaminetetraacetic acid (EDTA-Na $), 0.1 \mathrm{M}$ potassium ferricyanide, $0.1 \mathrm{M}$ potassium ferrocyanide, and $1.0 \%$ Triton $\mathrm{X}-100(\mathrm{v} / \mathrm{v})]$ and incubated at $37^{\circ} \mathrm{C}$ for durations from a few hours to overnight. Stained samples were cleaned with $70 \%$ ethanol and observed.

For the fluorometric assay, $0.1 \mathrm{~g}$ fresh tissue was first ground to a fine powder in liquid nitrogen, and then ground into a homogenate in $1 \mathrm{~mL}$ GUS extraction buffer $(100 \mathrm{mM}$ phosphate buffer, $\mathrm{pH} 8.0$, with $1 \% \mathrm{PVP}$ and $10 \mathrm{mM} \beta$-mercaptoethanol). The homogenate was placed on ice for $1 \mathrm{~h}$, and centrifuged at $13,000 \mathrm{rpm}$ for $10 \mathrm{~min}$ at $4^{\circ} \mathrm{C}$. The supernatant was transferred to GUS assay buffer and incubated at $37^{\circ} \mathrm{C}$ for $20 \mathrm{~min}$; the reaction was stopped using $0.2 \mathrm{M} \mathrm{Na}_{2} \mathrm{CO}_{3}$ and fluorescence measured using a $970 \mathrm{CRT}$ fluorescence spectrophotometer (Shanghai Analytical Instrument Factory). Meanwhile, the total protein content of the extracts was determined using the Bradford method (1976). Each sample was measured three times and the mean GUS activity for each independent line determined.

\section{Light-dependent development of GUS expression in transgenic tobacco plants}

To examine GUS activity in leaf tissue induced by light, transgenic plants were first grown in complete darkness at $25^{\circ} \mathrm{C}$ for 1 week. Plants were further cultured under a $16 / 8-\mathrm{h}$ light/dark regime. After 24, 48, 72, and $96 \mathrm{~h}$ of light treatment, GUS activity of young and old leaf blades was analyzed.

\section{RESULTS}

\section{Cloning of the soybean $r b c S$ promoter}

The 5'-flanking sequence of the soybean $r b c \mathrm{~S}$ promoter (TAIL1) was obtained using TAIL-PCR amplification with primers AD2, SP1, SP2, and SP3 (Figure 2, lanes 1-9). The fragment was ligated into pMD18-T. The fragment $r b c \mathrm{SP}$ was cloned through PCR using primers SS and SA with genomic Soybean Jinong 13 DNA as template (Figure 2, lane 10). $r b c \mathrm{SP}$ was then cloned into the pMD18-T vector to generate the pT- $r b c \mathrm{SP}$ recombinant plasmid (Figure 2, lanes 11 and 12).

\section{Sequence analysis of the soybean $r b c S$ promoter}

The cis-acting elements of the soybean $r b c \mathrm{~S}$ promoter ( $r b c \mathrm{SP})$ were analyzed using the PLACE and PlantCARE software. Several motif types were present in the promoter (Figure 3): 1) A/T rich and CAAT boxes upstream of the transcription start site; these serve as basal promoter elements for transcription. 2) GT binding site Box II (GGTTAA); this light-specific regulatory module was first identified in the pea $R B C S$-3A promoter, GT-elements evolved from Box II have been found in the promoter regions of many other genes and encode diverse functions (Green et al., 1987; Zhou, 1999). 3) Light-induced sequence G box (A/CCACGTG) 
or I box (GATAAG); mutations in the context of Arabidopsis rbcS-1A promoter substantially reduce the expression of $A d h$ and GUS reporter genes (Donald and Cashmore, 1990). 4) GATA motifs (WGATAR); these are implicated to act in the light-dependent and nitrate-dependent control of transcription in plants (Reyes et al., 2004). 5) Motifs with a known relationship to light including H box (CCTACC), REalpha element (AACCAA), and CCAAT-box (Song et al., 2000; Outchkourov et al., 2003; Qu et al., 2011). The cis-acting elements identified in $r b c$ SP strongly suggested that heterologous genes driven by $r b c$ SP could be induced in a lightspecific manner.

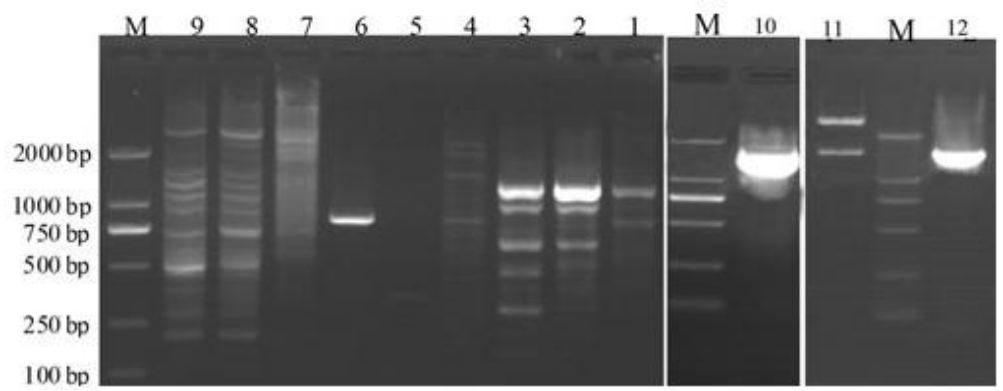

Figure 2. Analysis of TAIL-PCR products from the soybean $r b c \mathrm{~S}$ SRS4 promoter following $1 \%$ agarose electrophoresis and restriction digestions. Lane M: DL2000; lanes 1, 2, and 3: products of AD1 in the primary, secondary, and tertiary reactions; lanes 4, 5, and 6: products of AD2 in the primary, secondary, and tertiary reactions; lanes 7,8, and 9: products of AD3 in the primary, secondary, and tertiary reactions; lane 10: PCR product of the $r b c \mathrm{~S}$ promoter from soybean; lanes 11 and 12 : restriction digestion of $\mathrm{pT}-r b c \mathrm{~S}$ and PCR product of $\mathrm{pT}-r b c \mathrm{~S}$.

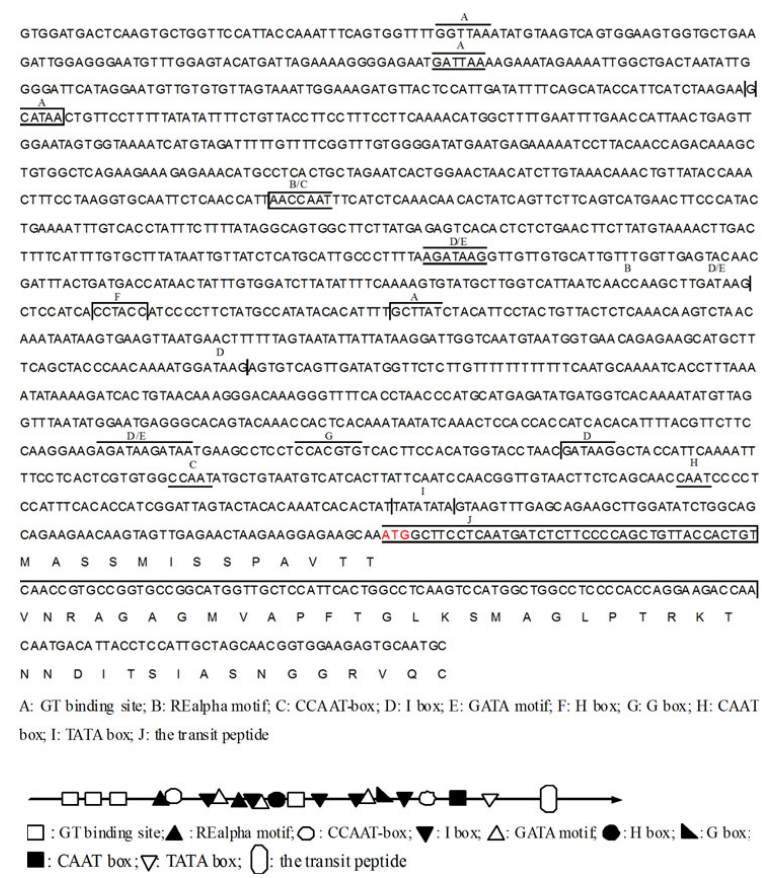

Figure 3. Sequence analysis of the soybean $r b c \mathrm{~S}$ promoter and schematic diagram summarizing the distribution of light-specific promoter related motifs within the nucleotide sequences of $r b c \mathrm{SP}$. 

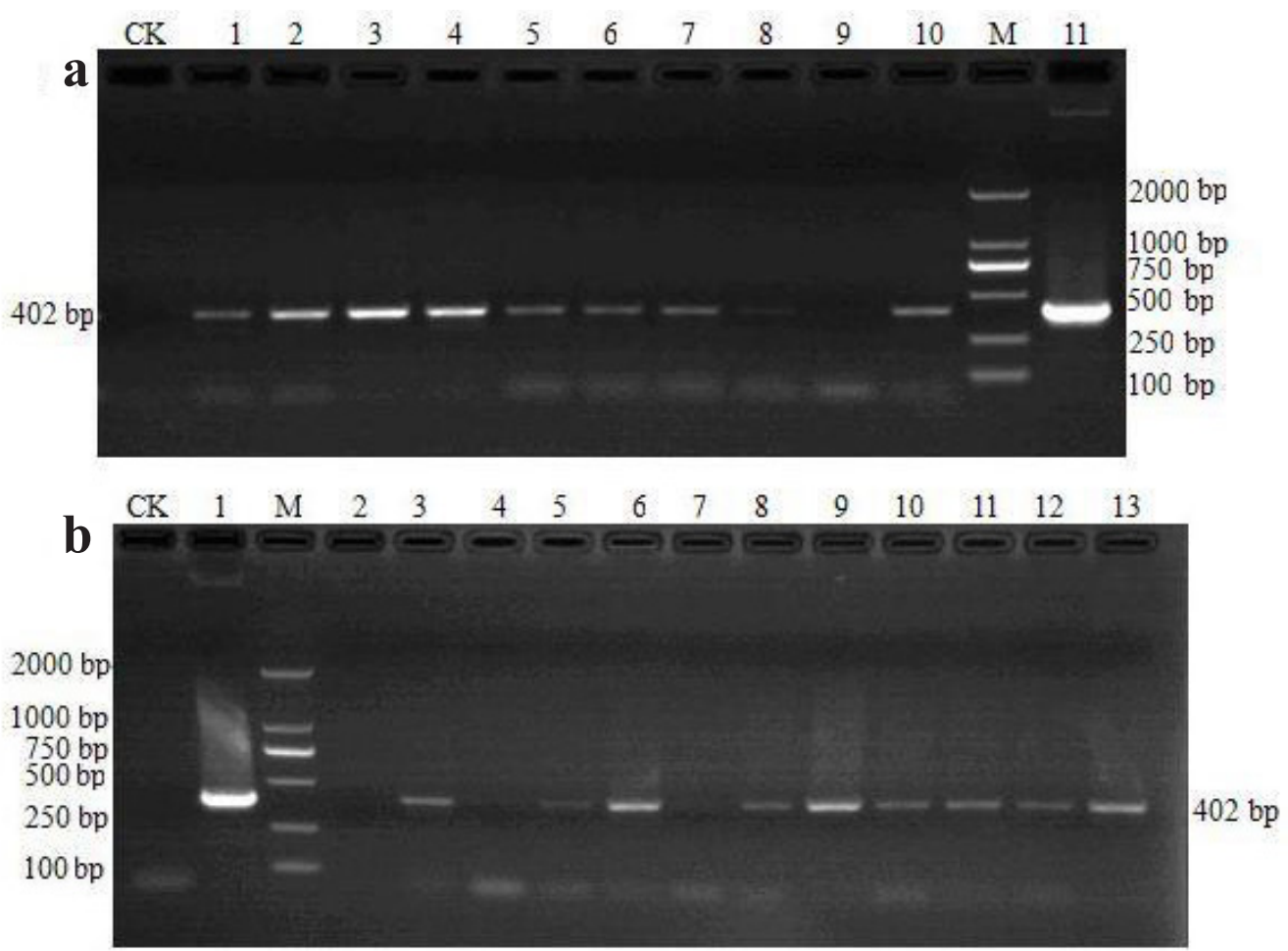

Figure 4. Identification of prbcSP plants (a) and p35SP plants (b) using PCR. a. Lane M: DL2000; lanes 1-10: the prbcSP plants; lane 11: pCAMBIA-GrbcSP vector; CK: the wild-type plant. b. Lane M: DL2000; lanes 2-13: the p35SP plants; lane 1: pCAMBIA1301 vector; CK: the wild-type plant.

\section{Expression analysis of the GUS gene under control of the soybean $r b c S$ promoter in transgenic tobacco}

PCR analysis was performed to confirm that the promoter was integrated into the genomic DNA of transgenic tobacco (Figure 4).

Histochemistry of leaves and roots from transgenic and wild-type plants was conducted to reveal the spatial expression pattern driven by the soybean $r b c S$ promoter (Figure $5 \mathrm{a}-\mathrm{c}$ ). In prbcSP plants, the GUS staining of leaf tissue was deep, but was only slight in the root. In p35SP plants, GUS staining was observed in both leaf and root tissue. No GUS activity was detected in the wild-type plants. Therefore, the GUS reporter gene in transgenic tobacco was expressed in a leaf-specific manner under the control of the soybean $r b c \mathrm{~S}$ promoter.

\section{Fluorescence analysis of GUS activity in transgenic tobacco}

Histochemical analysis does not provide a precise measure of GUS expression levels in different tissues. Therefore, GUS activity was assessed using a quantitative GUS assay in the transgenic plants. In prbcSP plants, GUS activity was mainly detected in the leaves, and was minimal in shoots and roots (Figure 5d); while in p35SP plants, GUS activity was consistent across all tissues. This result further confirms the leaf specificity of the $r b c \mathrm{~S}$ promoter. 


\section{Light induction of $r b c S P$-gusA in transgenic tobacco plants}

$r b c$ SP plants were germinated in the dark for 7 days and then exposed to light for 24,48 , 72 , or $96 \mathrm{~h}$. Old and young leaf blades from each plant were assayed for GUS activity (Figure 5e). GUS activity did not decrease in old blades transferred to the dark, but increased slightly, and then remained invariant following exposure to light. In younger blades, GUS activity decreased after being kept in darkness for 7 days, but continued to increase after light induction.
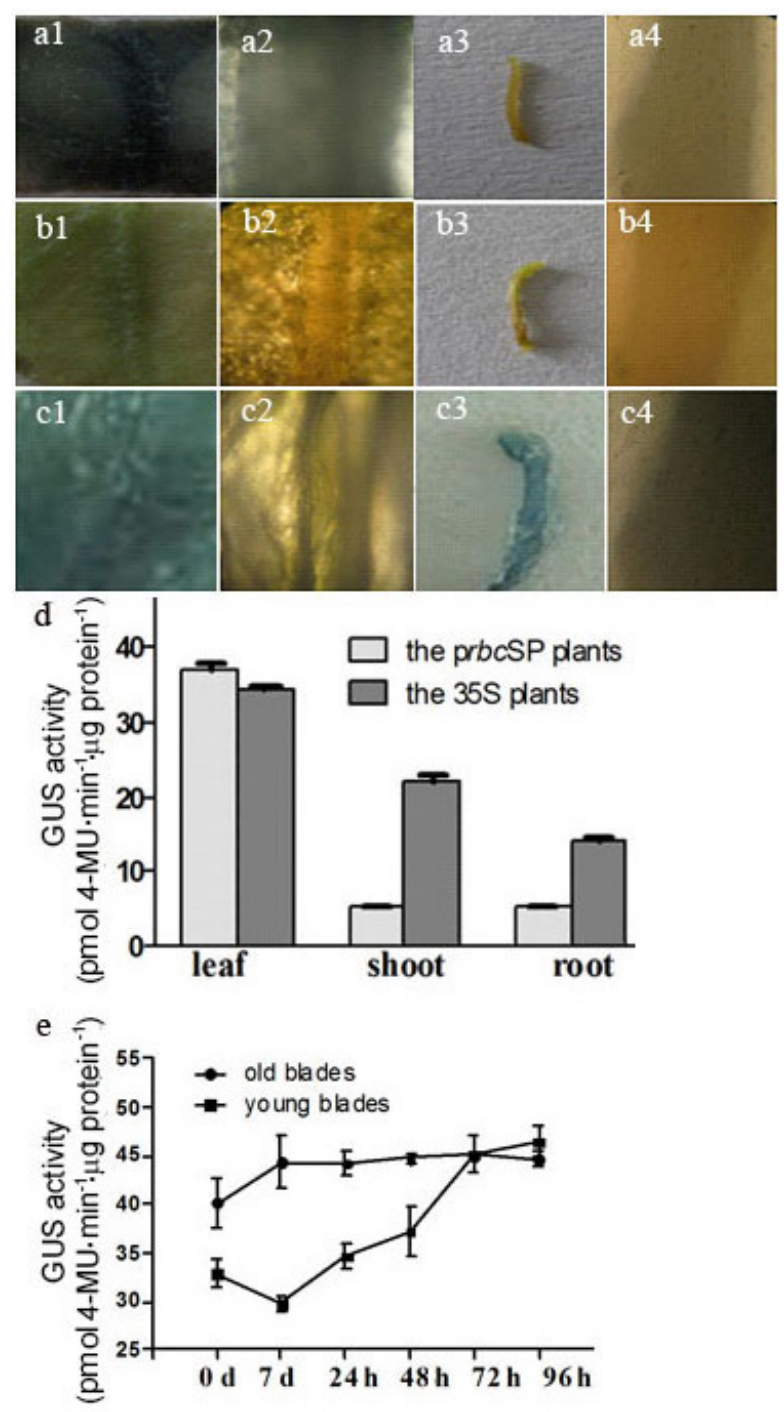

Figure 5. Analysis of GUS in transgenic and wild-type plants. a. b. and c. Expression of the gus gene in different tissues of the prbcS, wild-type, and p35S plants, respectively ( 1 and 2: leaf; 3 and 4: root; 1 and 3 were macroscopic; 2 and 4 were observed under the microscope); d. GUS activity in different tissues of transgenic plants; e. Light induction of gus expression in the prbcSP plants. 


\section{DISCUSSION}

TAIL-PCR enables convenient, quick, efficient, and specific cloning, and can therefore be used to obtain long DNA sequences proximal to a known gene. This technique has proven to be suitable for isolating powerful promoters (Terauchi and Kahl, 2000; Li et al., 2007). In this study, TAIL-PCR was successfully applied to clone the soybean $r b c$ S promoter. TAIL-PCR products can be achieved in a $0.2-2-\mathrm{kb}$ range (Liu and Whittier, 1995). The product generated in this study was only approximately $900 \mathrm{bp}$, despite the PCR procedure taking about $10 \mathrm{~h}$. A possible reason for the shortness of the TAIL1 sequence was the quantity of the arbitrary degenerate primers (only three primers), therefore further $\mathrm{AD}$ primers are required for future research.

TAIL-PCR provides an effective and convenient way to clone an unknown sequence adjacent to a known sequence. In this study, the soybean $r b c \mathrm{~S}$ promoter was cloned using both TAIL-PCR and general PCR. The length of the promoter was $1775 \mathrm{bp}$, and included several cis-acting elements implicated in transcriptional regulation by light in other higher plants.

To identify the expression pattern of the soybean $r b c S$ promoter, $r b c \mathrm{~S}$ promoter-GUS and $C a M V 35 \mathrm{~S}$ promoter-GUS fusion genes were transformed into tobacco. GUS staining and fluorescence analysis revealed that $G U S$ reporter gene expression driven by the soybean $r b c S$ promoter was only found in the leaves of transgenic tobacco plants (Figure 5a-d). The small quantity of GUS staining observed in the stems could be due to there being few chloroplasts. However, the unexpected GUS detection in the roots may be a result of leakage. In all transgenic tobacco plants, GUS driven by the CaMV $35 \mathrm{~S}$ promoter expressed constitutively. These results are comparable with previous studies (Baranski and Puddephat 2004; Baba-Kasai et al., 2005).

Meanwhile, Gus expression levels driven by the soybean $r b c S$ promoter in leaves were the same as those driven by the CaMV $35 \mathrm{~S}$ promoter (Figure $5 \mathrm{~d}$ ). Therefore, the soybean $r b c \mathrm{~S}$ promoter is a perfect substitute for the $35 \mathrm{~S}$ promoter in the leaf. The soybean $r b c \mathrm{~S}$ promoter can induce the expression of foreign genes possessing leaf-specific patterns in transgenic plants, reducing the burden of plants and effects on the agronomic traits of crops, and improving the concentration of the foreign gene in the particular part, thus, increasing the expression level of the foreign gene.

When transgenic tobacco plants containing the soybean $r b c \mathrm{~S}$ promoter were transferred between light and dark conditions, Gus expression levels controlled by the promoter were induced in younger leaves (raised in the presence of light, decreased in the absence of light). However, in older leaves, expression remained approximately the same across all time points (Figure 5e). Further investigation of this phenomenon is recommended for future study.

In conclusion, the isolation and sequence analysis of the soybean $r b c \mathrm{~S}$ promoter provides an important insight into the elements controlling foreign gene expression. This study indicates that the $r b c \mathrm{~S}$ promoter confers a high level of GUS expression in leaves, and is under light-regulation. Thus, the $r b c \mathrm{~S}$ promoter can be applied in transgenic research for the modification of crop quality.

\section{ACKNOWLEDGMENTS}

Research supported by grants from the Special Program for Research of Transgenic Plants (\#2014ZX08010-002), the National Science Foundation of China (\#31271746, \#31201144, \#31101091, and \#31171459), and the National Science Foundation of Jilin Province (\#201215178). 


\section{REFERENCES}

Baba-Kasai A, Hara N and Takano M (2014). Tissue-specific and light-dependent regulation of phytochrome gene expression in rice. Plant Cell Environ. 37: 2654-2666.

Bakhsh A, Qayyum RA, Shamim Z and Husnain T (2011). A mini review: RuBisCo small subunit as a strong, green tissuespecific promoter. Arch. Biol. Sci. 63: 299-307.

Baranski R and Puddephat IJ (2004). Tissue specific expression of $\beta$-glucuronidase gene driven by heterologous promoters in transgenic cauliflower plants. Acta Physiol. Plant. 26: 307-315.

Berry-Lowe SL and Meagher RB (1985). Transcriptional regulation of a gene encoding the small subunit of ribulose-1,5bisphosphate carboxylase in soybean tissue is linked to the phytochrome response. Mol. Cell. Biol. 5: 1910-1917.

Berry-Lowe SL, Mc Knight TD, Shah DM and Meagher RB (1982). The nucleotide sequence, expression, and evolution of one member of a multigene family encoding the small subunit of ribulose-1,5-bisphosphate carboxylase in soybean. J. Mol. Appl. Genet. 1: 483-498.

Bradford MM (1976). A rapid and sensitive method for the quantitation of microgram quantities of protein utilizing the principle of protein-dye binding. Anal. Biochem. 72: 248-254.

Bustamante CA, Civello PM and Martínez GA (2009). Cloning of the promoter region of $\beta$-xylosidase (FaXyll) gene and effect of plant growth regulators on the expression of FaXyll in strawberry fruit. Plant Sci. 177: 49-56.

Cho MJ, Widholm JM and Vodkin LO (1995). Cassettes for seed-specific expression tested in transformed embryogenic cultures of soybean. Plant Mol. Biol. Rep. 13: 255-269.

Dean C, Pichersky E and Dunsmuir P (1989). Structure, evolution, and regulation of RbcS genes in higher plants. Annu. Rev. Plant Physiol. Plant Mol. Biol. 40: 415-439.

Dhingra A, Portis AR and Daniell H (2004). Enhanced translation of a chloroplast-expressed $R b c \mathrm{~S}$ gene restores small subunit levels and photosynthesis in nuclear RbcS antisense plants. Proc. Nat. Acad. Sci. U.S.A. 101: 6315-6320.

Donald R and Cashmore AR (1990). Mutation of either G box or I box sequences profoundly affects expression from the Arabidopsis rbcS-1A promoter. EMBO J. 9: 1717-1726.

Gittins JR, Pellny TK, Hiles ER, Rosa C, et al. (2000). Transgene expression driven by heterologous ribulose-1,5bisphosphate carboxylase/oxygenase small-subunit gene promoters in the vegetative tissues of apple (Malus pumila Mill.). Planta 210: 232-240.

Grandbastien MA, Berry-Lowe SL, Shirley BW and Meagher RB (1986). Two soybean ribulose-1,5-bisphosphate carboxylase small subunit genes share extensive homology even in distant flanking sequences. Plant Mol. Biol. 7: 451-465.

Green PJ, Kay SA and Chua NH (1987). Sequence-specific interactions of a pea nuclear factor with light-responsive elements upstream of the $r b c S-3 A$ gene. EMBO J. 6: 2543-2549.

Horsch RB, Fry JE, Hoffmann NL, Eichholtz D, et al. (1985). A simple and general method for transferring genes into plants. Science 227: 1229-1231.

Jefferson RA (1987). Assaying chimeric genes in plants: the GUS gene fusion system. Plant Mol. Biol. Rep. 5: 387-405.

Khoudi H, Vézina LP, Mercier J, Castonguay Y, et al. (1997). An alfalfa rubisco small subunit homologue shares cisacting elements with the regulatory sequences of the RbcS-3A gene from pea. Gene 197: 343-351.

Kyozuka J, McElroy D, Hayakawa T, Xie Y, et al. (1993). Light-regulated and cell-specific expression of tomato $r b c S$ gusA and rice rbcS-gusA fusion genes in transgenic rice. Plant Physiol. 102: 991-1000.

Li Q, Yin H, Li D, Zhu H, et al. (2007). Isolation and characterization of CMO gene promoter from halophyte Suaeda liaotungensis K. J. Genet. Genomics 34: 355-361.

Liu YG and Whittier RF (1995). Thermal asymmetric interlaced PCR: automatable amplification and sequencing of insert end fragments from P1 and YAC clones for chromosome walking. Genomics 25: 674-681.

Marraccini P, Courjault C, Caillet V, Lausanne F, et al. (2003). Rubisco small subunit of Coffea arabica: cDNA sequence, gene cloning and promoter analysis in transgenic tobacco plants. Plant Physiol. Biochem. 41: 17-25.

Nagy F, Morelli G, Fraley RT, Rogers SG, et al. (1985). Photoregulated expression of a pea $r b c \mathrm{~S}$ gene in leaves of transgenic plants. EMBO J. 4: 3063-3068.

Outchkourov NS, Peters J, de Jong J, Rademakers W, et al. (2003). The promoter-terminator of chrysanthemum rbcS1 directs very high expression levels in plants. Planta 216: 1003-1012.

Qu D, Song Y, Li WM, Pei XW, et al. (2011). Isolation and characterization of the organ-specific and light-inducible promoter of the gene encoding rubisco activase in potato (Solanum tuberosum). Genet. Mol. Res. 10: 621-631.

Quandt HJ, Broer I and Puhler A (1992). Tissue-specific activity and light-dependent regulation of a soybean $r b c \mathrm{~S}$ promoter in transgenic tobacco plants monitored with the firefly luciferase gene. Plant Sci. 82: 59-70.

Reyes JC, Muro-Pastor MI and Florencio FJ (2004). The GATA family of transcription factors in Arabidopsis and rice. Plant Physiol. 134: 1718-1732.

Song P, Heinen JL, Burns TH and Allen RD (2000). Expression of two tissue-specific promoters in transgenic cotton 
plants. J. Cotton Sci. 4: 217-223.

Spreitzer RJ (2003). Role of the small subunit in ribulose-1,5-bisphosphate carboxylase/oxygenase. Arch. Biochem. Biophys. 414: 141-149.

Terauchi R and Kahl G (2000). Rapid isolation of promoter sequences by TAIL-PCR: the 5'-flanking regions of Pal and Pgi genes from yams (Dioscorea). Mol. Gen. Genet. 263: 554-560.

Wang G and $\mathrm{Xu}$ Y (2008). Hypocotyl-based Agrobacterium-mediated transformation of soybean (Glycine max) and application for RNA interference. Plant Cell Rep. 27: 1177-1184.

Zhong H, Teymouri F, Chapman B, Maqbool SB, et al. (2003). The pea (Pisum sativum L.) rbcS transit peptide directs the Alcaligenes eutrophus polyhydroxybutyrate enzymes into the maize (Zea mays L.) chloroplasts. Plant Sci. 165: 455-462.

Zhou DX (1999). Regulatory mechanism of plant gene transcription by GT-elements and GT-factors. Trends Plant Sci. 4: 210-214. 